\title{
THE ANALYSIS OF SMARTPHONE APPS IN GEOMATICS EDUCATION
}

\author{
Tee-Ann Teo ${ }^{\mathrm{a}, *}$, Hsien-Ming Wu ${ }^{\mathrm{b}}$, Tian-Yuan Shih ${ }^{\mathrm{c}}$, Fuan Tsai ${ }^{\mathrm{d}}$ \\ ${ }^{a}$ Dept. of Civil Engineering, National Chiao Tung University, Hsinchu, Taiwan 30010 - tateo@mail.nctu.edu.tw \\ ${ }^{\mathrm{b}}$ Dept. of Civil Engineering, National Chiao Tung University, Hsinchu, Taiwan 30010 - cheminwu@gmail.com \\ ${ }^{c}$ Dept. of Civil Engineering, National Chiao Tung University, Hsinchu, Taiwan 30010 - tyshih@mail.nctu.edu.tw \\ ${ }^{\mathrm{d}}$ Center for Space and Remote Sensing Research, National Central University, Taoyuan, Taiwan 32001 - \\ ftsai@csrsr.ncu.edu.tw
}

\section{Commission VI}

KEY WORDS: Applications (Apps), geomatics, smartphone, education

\begin{abstract}
:
Geomatics is a discipline of collecting, processing and analysing geospatial data. Data collection is a core process of geomatics which usually adopt precise equipment to measure geospatial data. With the development of technology, a smartphone in this present era is not simply for communication; several low cost measurement devices such as Global Positioning System (GPS), gyro and camera are assembled in a smartphone. Although the devices assembled in a smartphone could not meet the needs of accuracy requirement for many geomatics applications, millions of mobile applications (Apps) can be downloaded and installed from Google Play and Apple Store freely, and a variety of sensors can be chosen for user. Considering that the popularity and convenience of a smartphone, and assuming that the accuracy of those collected data is acceptable for learning purposes, it is expected that a smartphone can be employed in geomatics for hand-on education. For example, Vespucci OSM Editor is an App to edit the OpenStreetMap on Android. The user may have the hand-on experience on GPS positioning, web services and mapping via Vespucci OSM Editor. The aim of this paper is to collect and analyze different Apps for geomatics education. The Apps are classified into four categories, namely, surveying, remote sensing, GPS and Geographic Information System (GIS). In this paper, more than 20 free Apps are collected and analysed for different hand-on studies in geomatics education. Finally, all the related Apps are listed on a website for updating.
\end{abstract}

\section{INTRODUCTION}

The purpose of geomatics is obtaining useful geospatial information for decision makers through data collection, data analysis and visualization. There are several instruments to collect precise data, for example, total station for distance and angle measurements, digital level for height measurement, GPS for positioning, metric camera for aerial photo, radar and lidar for surface modelling. An integrated mobile mapping system usually includes positioning and orientation system (POS) and data acquisition sensors. Survey-grade POS integrates GPS and inertial navigation system (INS) to obtain the positions of (X, $\mathrm{Y}, \mathrm{Z}$ ) and orientations (omega, phi, kappa) of sensors. POS are usually used in direct dereferencing. The data acquisition sensors can be a laser scanner and a digital camera.

With the advances in technology, a mobile device such as smartphone and tablet are now integrated with variety of sensors like non-metric digital camera, low-cost GPS, accelerometer, gyroscope. Therefore, mobile devices are now equipped with multiple functions, providing additional functionality beyond voice communication. Smartphones are changing people's lifestyle. Most of the smartphone companies offer different types of mobile applications (Apps) to increase and improve the functionalities of a smartphone. So far, millions of mobile applications (Apps) have been developed and can be downloaded from Google Play and Apple Store for Andriod and IOS systems, respectively.

Since a smartphone (or tablet) is able to connect to internet, many researchers study on the possibility of using smartphone in education. Therefore, one of the most important categories in
Google Play and Apple Store is 'education'. Most of the educational Apps are in foreign language and literacy (Chiong and Shuler, 2010). Shuler (2009) indicated that Apps are unquestionably a new medium for providing educational content to children nationwide, both in terms of their availability and popularity. Shuler (2012) also considered that children will benefit if apps become an important force for learning and discovery. Dalziel and Dalziel (2013) showed that tablet devices can be used to create app-based learning designs, for example, design in medical education. Schauppenlehner et al., (2012) also discussed the possibility of Apps development within a research and education cooperation.

Some websites also collect and introduce educational Apps on specific topics. For example, Howell (2014) collect GIS-related Apps http://geoawesomeness.com/free-gis-apps-google-playstore/. We can also find the top 10 Apps for K-6 education at http://educationappreviews.com/. Thus, the potential value of Apps for education is widely realised in different disciplines. However, most of the researchers have discussed about educational Apps in language and literacy, relatively few studies were on geomatics-related education.

Millions of mobile Apps can be downloaded and installed from Google Play and Apple Store. Among these Apps, some specific Apps contain measurement functions which can provide distance, angle, area, location and other information. Although the measurement devices assembled in a smartphone could not meet the needs of accuracy requirement for many geomatics applications, they still can serve as rough reference information. Therefore, these Apps can be used to support geomatics teaching so that students can use their own smartphones to 
understand the theory and algorithm behind those Apps. Some of the open data community have also developed Apps in collaborative mapping, for example, openstreetmap.org. The users collect GPS trajectory, refine, and upload to database through the App.

In order to understand the availability of geomatic-related Apps, the aim of this paper is to collect and analyze different Apps for geomatics education. Moreover, all of the collected Apps are listed in a website for reference.

In early 1990s, mobilephones had started the wireless communication technology. The appearance of mobilephones have gradually changed toward miniaturization, thin and multifunction. In early 2000s, a mobilephone had begun to integrate camera devices and basic phone communication modules. The resolution of camera had developed from 100,000 pixels to $10,000,000$ pixels level. Besides, the $3 \mathrm{G}$ and $4 \mathrm{G}$ had also provided internet services for mobilephones' users. Hence, communication capability has developed from voice call to video call.

Nowadays, a smartphone basically has built-in acceleration sensors (G-sensor), direction sensors (gyroscope), magnetic sensors (M-sensor), light sensors and global positioning system. Some of the smartphones had even installed pressure sensors and temperature sensors. These sensors measure data to meet the different applications of smartphones. Below are the descriptions of each sensor:

1. Accelerometer (G-sensor): to measure the object's acceleration due to external forces in three-dimensional space, and calculate the displacement.

2. Direction sensor (Gyroscope): to measure the object's rotation angle based on conservation of angular momentum.

3. Magnetic sensors (M-sensor): to detect the direction of Earth's magnetic field based on magneto-electric conversion theory.

4. Light sensor: to sense the intensity of light surrounding the object and adjust the screen brightness or as photographs parameters.

5. GPS: to receive the positioning satellite signals and determine the location of an object in WGS84 coordinate.

6. Pressure sensors: to measure the pressure surrounding the object, and calculate the altitude of the object based on the data.

7. Temperature sensors: to obtain the local temperature, the working principle is to use the relationship between temperature and resistance.

As a smartphone is equipped with different sensors, a smartphone is not only a mobilephone. It can be treated as a multi-function device. In order to meet the different needs, millions of mobile Apps have been developed. Users can access the data acquired by sensors from different Apps. Hence, smartphones have become an important bridge for the realization of intelligent life.

A content analysis was conducted to analyze the geomatics category of the Apps. The scheme of this study includes three major steps. First, we search the related Apps from Google Play and Apple Store via specific keywords (e.g. surveying, GIS, GPS, etc). Then, we download, install and evaluate the functions of those Apps. Second, all Apps are classified into four different categories (i.e. surveying, photogrammetry and remote sensing, GIS and GPS) according to the applications. The functions of Apps are compared to the algorithm of geomatics. Finally, we analyze the statistics and vote of Apps for different category.

\section{GEOMATICS APPS}

Many geomatics Apps use the built-in sensors of smartphones to measure distances, angles, areas, three-dimensional coordinates and others. It can also link to a web map for data editing as well as navigation. Although the measurement accuracy of the devices assembled in a smartphone is not as good as professional equipment, it can be used to collect and roughly estimate the information. In this study, the accuracy of a smartphone's sensors is not the major concern. The major consideration is utilizing the smartphone as a mobile mapping device in geomatics education.

The collected Apps are classified into four categories: surveying, photogrammetry and remote sensing, global positioning system, and geographic information system. These four categories are the most common subjects in geomatics education. Table 1 is the descriptions of the four categories related to Apps' functions.

Table 1. Descriptions of the four categories.

\begin{tabular}{|c|l|}
\hline Category & \multicolumn{1}{|c|}{ Descriptions } \\
\hline Surveying & $\begin{array}{l}\text { To use the sensors of a smartphone in } \\
\text { angle, distance, height and area } \\
\text { measurements. }\end{array}$ \\
\hline GPS & $\begin{array}{l}\text { To employ the GPS sensors in satellites } \\
\text { distributions and obtain locations in a } \\
\text { geographic coordinate system (or in } \\
\text { geographic coordinate systems). }\end{array}$ \\
\hline GIS & $\begin{array}{l}\text { To provide web-GIS services, map } \\
\text { updating, and, combined with GPS to } \\
\text { offer navigation or directions. }\end{array}$ \\
\hline $\begin{array}{c}\text { Photogrammetry } \\
\text { and remote } \\
\text { sensing }\end{array}$ & $\begin{array}{l}\text { To combine the camera and GPS/IMU } \\
\text { for images mosaicking and applications } \\
\text { of close-range photogrammetry. }\end{array}$ \\
\hline
\end{tabular}

In this study, thirty-one free Apps are collected and listed on a website. Table 2 lists the related information of these collected Apps. This study also creates a webpage to collect the geomatics related Apps. The URL of the webpage is https://sites.google.com/site/nctuce/home/teaching/app. The number of downloads and votes from Google Play's users are also added in the webpage. These statistical numbers can be considered as an index of these Apps' ranking. The following will illustrate the possibilities of using Apps in geomatics education.

\subsection{Surveying}

In surveying education, trigonometry is a fundamental subject. It measures an angle directly and calculates the unknown distance indirectly. Traditionally, trigonometry is implemented by specialized equipment like altazimuth. Figure 1a shows an example of trigonometry using altazimuth. The observations are angle and length of $S$. The distance $D$ is calculated by simple trigonometry.

The idea of trigonometry can be implemented by a smartphone. Although smartphones does not have active laser ranging sensor to measure the distance directly, the distance can be calculated indirectly based on the built-in IMU (angle measurement) and 
the height of a target. Some of the Apps can be used to calculate the angle, distance and area as well. Figure 1b shows an example of trigonometry using a smartphone. Given the height of a target, the observation is the view angle of the target. The distance $D$ can be calculated roughly. Hence, a student can use the surveying App in a smartphone to practice the idea of trigonometry.

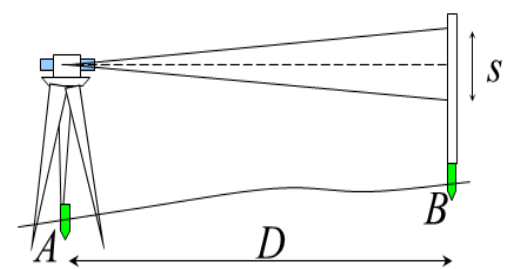

(a) Trigonometry using altazimuth.

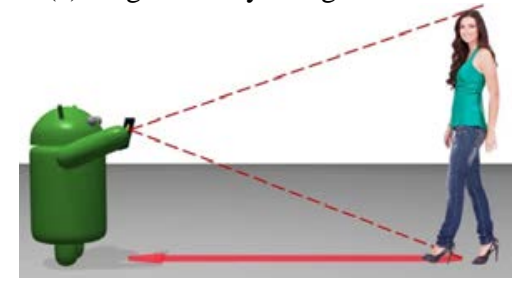

(b) Trigonometry using a smartphone (Google Play, 2014) Figure 1. Illustrations of trigonometry.

For example, Smart Measure is an App on Android system. It can calculate the distance between 1-50 meters, and also the height of an object. Figure 2 illustrates the measurements of the object's height. In this App, a user would have to key-in the height of a smartphone first. Then, the line-of-sign of the camera axis is aiming at the bottom of the object. The Smart Measure App will calculate the on ground horizontal distance based on the angle measurement automatically. Finally, the lineof-sign of the camera axis is aiming at the top of the object to calculate the height of the object.

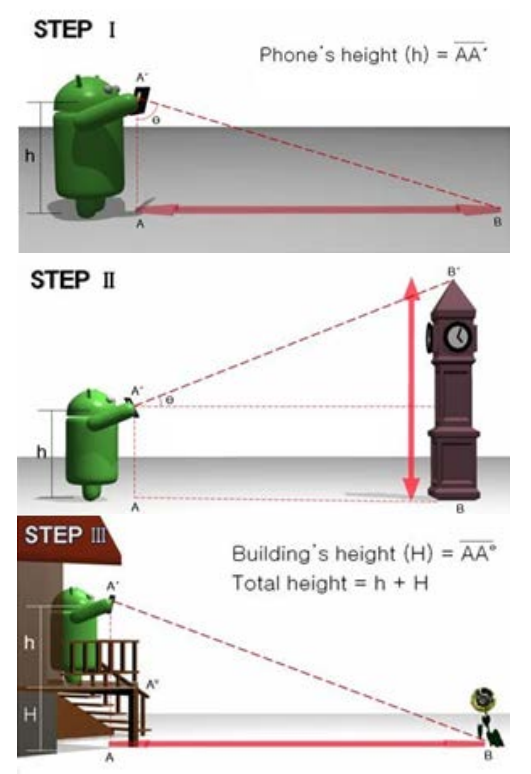

Figure 2. The process of using Smart Measure App. (Google Play, 2014)
Table 2. Geomatics-related Apps.

\begin{tabular}{|c|c|c|c|}
\hline Category & APP & Downloads* & Votes* \\
\hline Surveying & $\begin{array}{l}\text { Sensor Box } \\
\text { Plugin }\end{array}$ & 985 & 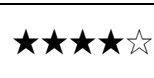 \\
\hline Surveying & AndroSensor & 4,175 & 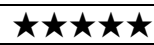 \\
\hline Surveying & Smart Measure & 39,707 & 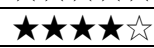 \\
\hline Surveying & Surveyor & 1,744 & 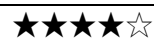 \\
\hline Surveying & $\begin{array}{c}\text { Measure Tape } \\
\text { HD Lite }\end{array}$ & - & - \\
\hline GPS & $\begin{array}{l}\text { Satellite Check- } \\
\text { GPS Status }\end{array}$ & 889 & 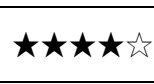 \\
\hline GPS & $\begin{array}{c}\text { GPS Status \& } \\
\text { Toolbox }\end{array}$ & 72,209 & 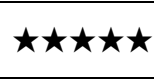 \\
\hline GPS & GPS Test & 27,064 & 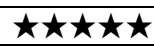 \\
\hline GPS & $\begin{array}{c}\text { GPS Area } \\
\text { Measurement }\end{array}$ & 314 & 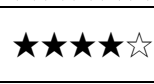 \\
\hline GPS & Land Surveyor & 50 & 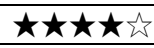 \\
\hline GIS & $\begin{array}{l}\text { 2GIS: maps \& } \\
\text { business listings }\end{array}$ & 139,888 & 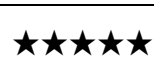 \\
\hline GIS & ArcGIS & 886 & $\star \star \star \star \star \star \star \lambda$ \\
\hline GIS & GIS & 33 & 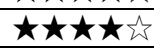 \\
\hline GIS & $\begin{array}{l}\text { GIS Mobile - } \\
\text { Imperious }\end{array}$ & 33 & 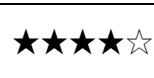 \\
\hline GIS & DataPoint GIS & 6 & 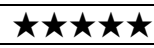 \\
\hline GIS & GIS Survey & 15 & 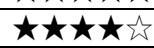 \\
\hline GIS & MapWithUs GIS & 13 & 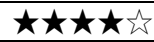 \\
\hline GIS & Wolf-GIS & 7 & 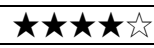 \\
\hline GIS & Mobile GIS & 2 & 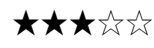 \\
\hline GIS & $\begin{array}{c}\text { Anywhere GIS } \\
\text { Free }\end{array}$ & 7 & $\star \star \star \star \star \star え$ \\
\hline GIS & Indoor GPS & 273 & 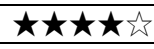 \\
\hline GIS & OSMtracker & 726 & 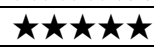 \\
\hline GIS & $\begin{array}{l}\text { Vespucci OSM } \\
\text { Editor }\end{array}$ & 318 & 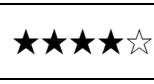 \\
\hline GIS & Dailyroads & 11,351 & 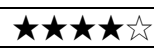 \\
\hline GIS & FootPath 2 & 1 & 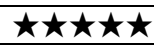 \\
\hline P\&RS & $\begin{array}{c}\text { Panorama } 360^{\circ} \\
\text { Camera }\end{array}$ & - & $\star \star \star \star \star \star え$ \\
\hline P\&RS & GeoCam & 419 & $\star \star \star \star \star \star \lambda$ \\
\hline P\&RS & $\begin{array}{c}\text { Depth Of Field } \\
\text { Calculator }\end{array}$ & 718 & 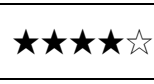 \\
\hline P\&RS & $\begin{array}{c}\text { Sun Surveyor } \\
\text { Lite }\end{array}$ & 1,237 & $\star \star \star \star \star え$ \\
\hline P\&RS & MagicPlan & - & 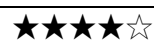 \\
\hline P\&RS & $\begin{array}{c}\text { Microsoft } \\
\text { Photosynth }\end{array}$ & - & - \\
\hline Remark & \multicolumn{3}{|c|}{ * on March 10, 2014} \\
\hline
\end{tabular}

\subsection{Global Positioning System}

Smartphones use the built-in GPS receiver to receive satellite signals and calculate the spatial location according to the GPS's signals. The positioning accuracy depends on the availability of signals and the distribution of satellites. For example, geometric dilution of precision (GDOP) should be considered in GPS field work. In GPS education, a student can use a smartphone to get his or her location including latitude, longitude, height, accuracy of points, and etc. Some Apps also provide satellite distributions and signal strength.

For example, GPS Status \& Toolbox is an App on Android system. The interface of this App is simple and easy to use. It provides the spatial coordinates and the satellite information, including the satellite number, spatial orientation and the signal 
strength. Users can reset it or download A-GPS data regularly for faster fixes. Figure 3 shows the interface of this App.

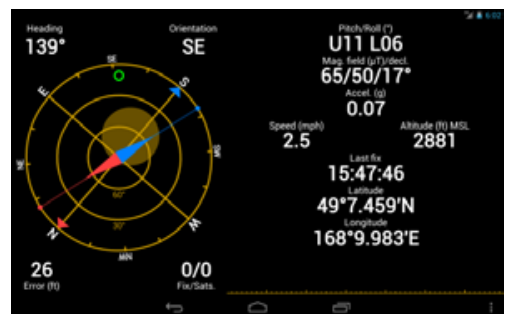

Figure 3. The interface of GPS Status \& Toolbox.

\subsection{Geographic Information System}

The GIS-based Apps in a smartphone are the most popular Apps among these four categories. In order to provide locationbased service (LBS), GIS-based Apps usually combines webGIS services and GPS positioning. LBS may provide the information surrounding the user through data base from the Internet or localhost. One of the most popular applications is route planning.

Some of the GIS-based Apps also provide editing functions. For example, Vespucci OSM Editor is an App for openstreetmap (OSM). Vespucci OSM Editor can download the map data for a specific area, and users can edit the digital map from OSM. After editing, the results can be uploaded to the OSM server directly. User can choose between an 'EasyEdit' mode with all operations or individual operations to perform. Any accidental change can be undone and all changes are listed for review before uploading. Figure 4 shows the interface of this App. Users may have the hand-on experience on GPS positioning, web-GIS, map updating and mapping via Vespucci OSM Editor. Moreover, they could earn the fundamental concept of GIS.

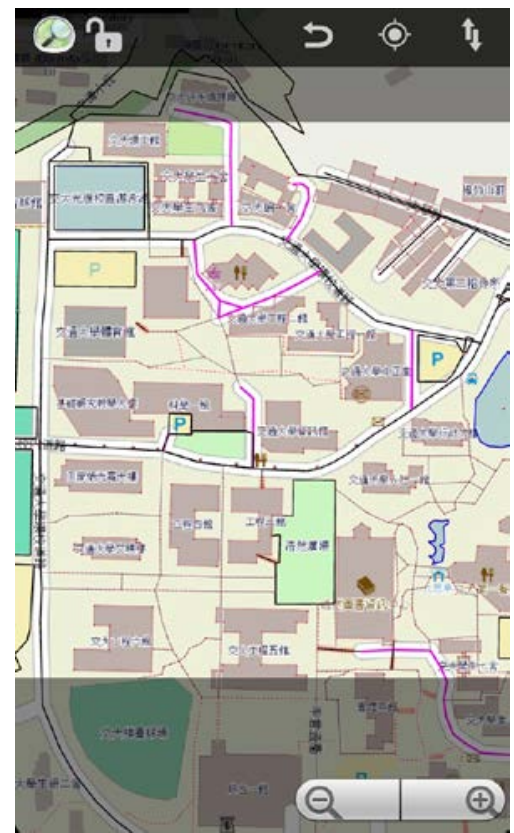

Figure 4. The map of Vespucci OSM Editor.

\subsection{Photogrammetry and Remote Sensing}

Photogrammetry and Remote Sensing is a technique to obtain reliable data and information without contact. The color and shape information of an object can be obtained by a camera.
Hence, the smartphone built-in camera can be used in this category. Moreover, the GPS/IMU of a smartphone may provide initial orientation for each image. The user may have the hand-on experience of close-range photogrammetry and remote sensing via a smartphone. For example, MagicPlan is an App for indoor mapping in Apple IOS. The algorithm of ray tracing has been implemented in MagicPlan. The ideas of ray tracing and direct georeferencing can be introduced though this App.

Image registration is an important step in data preprocessing. Image registration includes four major steps: feature detection, feature matching, transformation model estimation and image resampling. The image registration function for a panorama image has been implemented in a smartphone. For example, Pano Camera and Microsoft PhotoSynth are Apps on Apple IOS system. In these Apps, overlapped images are transformed into one unify coordinate system by searching the feature points. Figure 5a shows the interface of taking images on Pano Camera. After processing, Figure 5b shows the mosaicked image and Figure $5 c$ shows the final results.

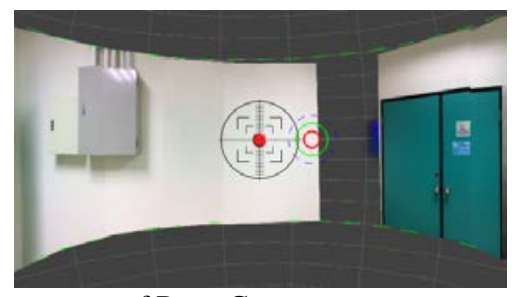

(a) Imaging process of Pano Camera.

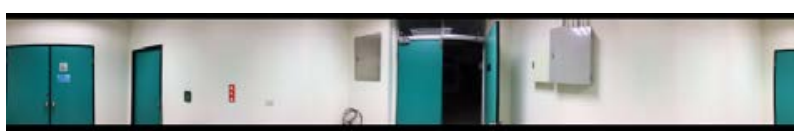

(b) Rectified panorama image.

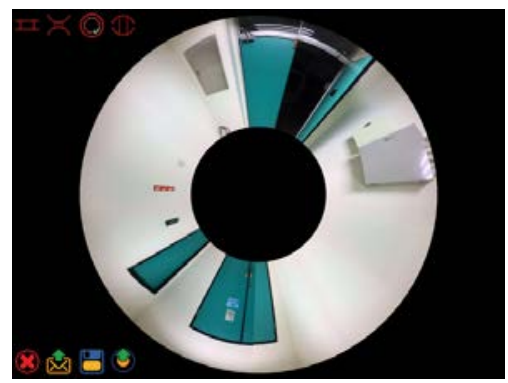

(c) Results of Pano Camera.

Figure 5. Illustrations of Pano Camera.

\section{ANALYSIS AND COMPARISON}

In this section, we collected the statistical numbers of downloads and votes of each App. These numbers were classified into four categories. Figure 6 shows the average downloads for each category. The results indicated that the GPS category is the most widely used and the average of downloads is about 20,000. The photogrammetry and remote sensing is relatively less downloaded when compared to others. This means, most people know about GPS Apps than photogrammetry and remote sensing Apps. 


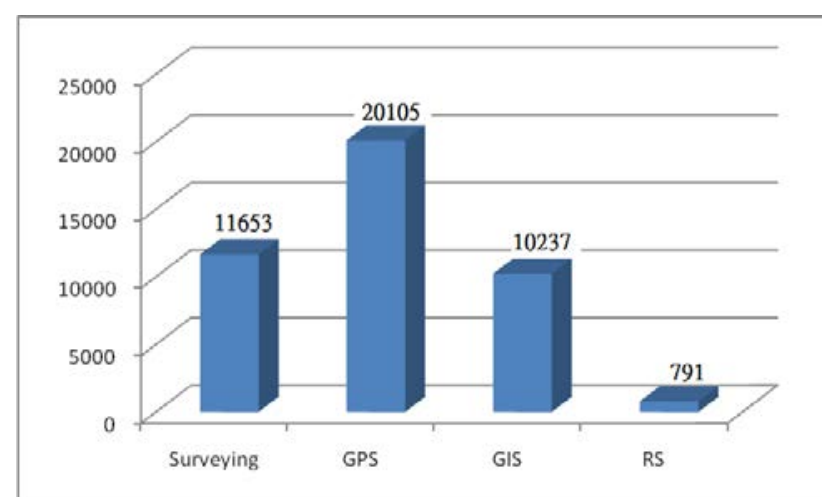

Figure 6. The average downloads.

Figure 7 is the average votes for each category. The highest grade of votes in Google Play is 5. All these categories were higher than grade 4 . Although these Apps could not provide high accuracy measurement, most people are satisfied with these Apps.

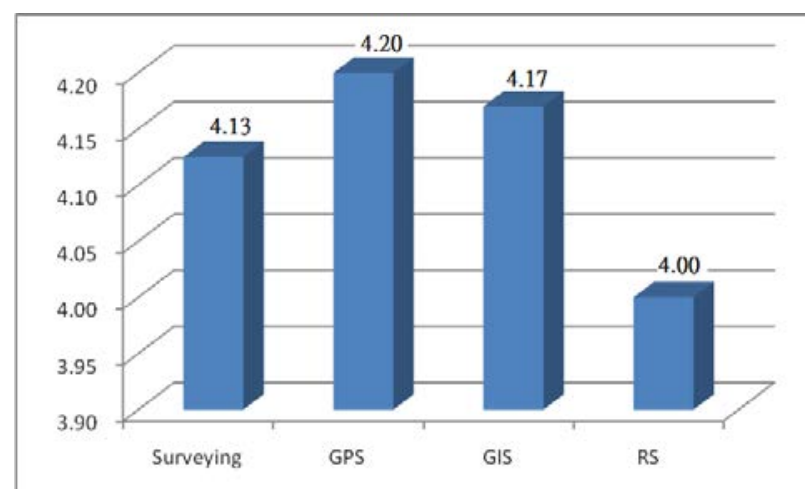

Figure 7. The average votes

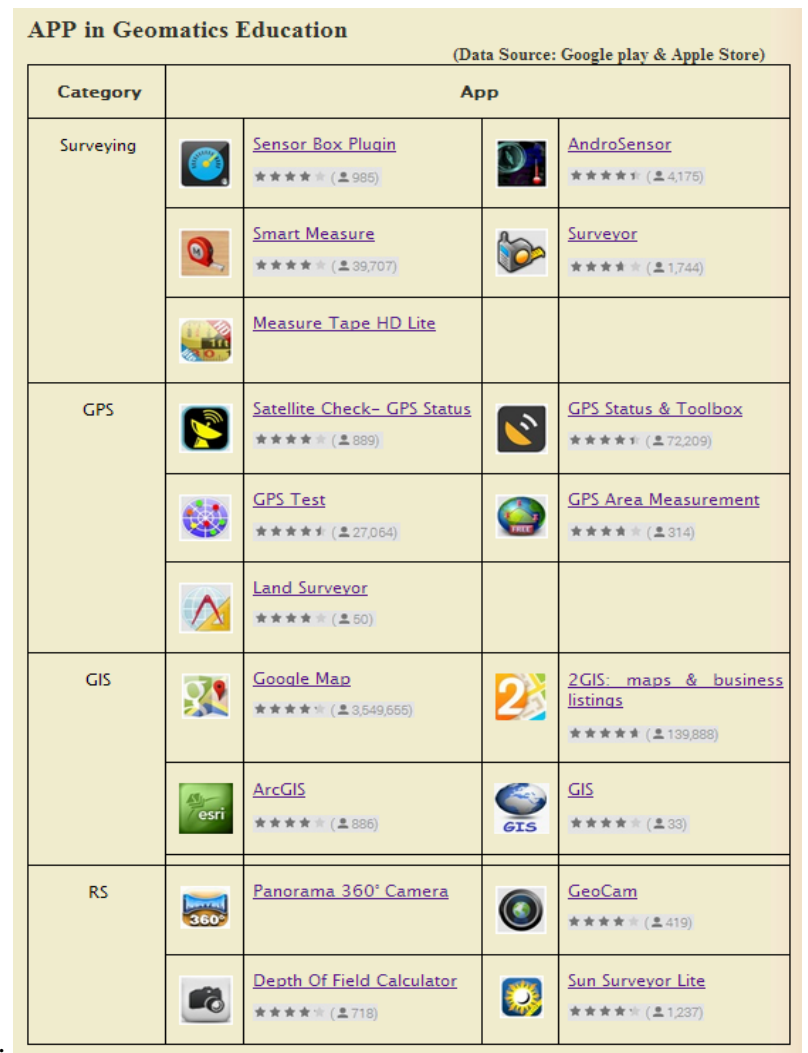

Figure 8. The website of Apps in geomatics education.

\section{CONCLUSIONS}

In this study, the smartphone Apps in geomatics education were briefly introduced. This study also created a webpage to collect these geomatics related Apps. Figure 8 shows the screenshot of the webpage. Considering that the popularity and convenience of a smartphone, and assuming that the accuracy of those collected data is acceptable for learning purpose, a smartphone can be employed in geomatics for hand-on education. The advantage of using Apps in education is to have hand-on experience anytime and anyplace independently. Moreover, when combining various sensors and Apps in geomatics education, there is a great potential for connecting different subjects in a geomatics education.

\section{REFERENCES}

Chiong, C. and Shuler, C., 2010. Learning: Is there an app for that? Investigations of young children's usage and learning with mobile devices and apps. The Joan Ganz CooneyCenter at Sesame Workshop, New York.

Dalziel, B. and Dalziel, J., 2013. Prospects for iPad Apps and Learning Design in Medical Education. Electric Dreams. Proceedings ascilite 2013 Sydney. pp. 206-209.

Google Play, 2014. Smart Measure, https://play.google.com/store/apps/details?id=kr.sira.measure\&h l=zh_TW (24 Mar. 2014).

Howell, D.M., 2014. Free GIS Apps on the Google Play Store, http://geoawesomeness.com/free-gis-apps-google-play-store/ (24 Mar. 2014).

Schauppenlehner, T., Blamhofer, S., Horn, M., et al., 2012. Can We Make an App for that? Integration of School Students within a Research-education Cooperation, GI Forum 2012: Geovizualisation, Society and Learning.

Shuler, C., 2009. iLearn: A Content Analysis of the iTunes App Store's Education Section. The Joan Ganz Cooney Center at Sesame Workshop, New York.

Shuler, C., 2012. iLearn II: An Analysis of the Education Category of the iTunes App Store. The Joan Ganz Cooney Center at Sesame Workshop, New York. 